\title{
Evaluation of the Initial 12 Months of a Routine Cryptococcal Antigen Screening Program in Reduction of HIV-Associated Cryptococcal Meningitis in Uganda
}

Kagimu Enock ( $\square$ kanockenock@gmail.com )

school of medicine,College of health sciences,Makerere University

Kiwanuka Julius

School of public health, Makerere University

Bridget C Griffith

School of public health, University of Minnesota, division of epidemiology

Derrick Bary Abila

school of medicine,College of health sciences,Makerere University

Morris K Rutakingirwa

Infectious diseases institute, makerere University college of health sciences

John Kasibante

Infectious diseases institute, makerere University college of health sciences

Kiiza Tadeo Kandole

Infectious diseases institute, makerere University college of health sciences

Richard Kwizera

Infectious diseases institute, makerere University college of health sciences

\section{Aggrey Semeere}

School of public health, Makerere University

\section{David B Meya}

school of medicine,College of health sciences,Makerere University

\section{Research Article}

Keywords: Cryptococcal Antigenemia (CrAg), Cryptococcal meningitis(CM), ART

Posted Date: August 10th, 2021

DOl: https://doi.org/10.21203/rs.3.rs-778682/v1

License: (a) This work is licensed under a Creative Commons Attribution 4.0 International License. Read Full License 
Page 2/16 


\section{Abstract}

\section{Background:}

Asymptomatic Cryptococcal Antigenemia (CrAg) patients develop meningitis within a month of testing positive. Pre-emptive antifungal therapy can prevent progression to Cryptococcal meningitis(CM). In April 2016, a national CrAg screening program was initiated in 206 high-volume health facilities that provide antiretroviral therapy in Uganda. We report the evaluation of the CrAg screening cascade focusing on linkage to care, fluconazole therapy for 10 weeks, and ART initiation in a subset of facilities.

\section{Methods:}

We conducted a retrospective, cross-sectional survey of patients with CD4<100 at seven urban and seven rural facilities after one year of program implementation. We quantified the number of patients who transitioned through the steps of the CrAg screening cascade over six-months follow-up. We defined cascade completion as a prophylactic fluconazole prescription. We conducted semi-structured interviews with lab personnel and clinic staff to assess functionality of the CrAg screening program. Data was collected using REDCap.

\section{Results:}

We evaluated 359 patient records; the majority (358/359, 99.7\%) were from government owned health facilities and just over half $(193 / 359,53.8 \%)$ had a median baseline CD4 cell count of $<50 \mathrm{cell} / \mu \mathrm{L}$. Overall, CrAg screening had been performed in $255 / 359(71.0 \%, 95 \% \mathrm{Cl}, 66.0-75.7)$ of patients' records reviewed, with a higher proportion among urban facilities $(170 / 209(81.3 \%, 95 \% \mathrm{Cl}, 75.4-86.4))$ than rural facilities (85/150 (56.7\%, 95\% Cl, 48.3-64.7)). Among those who were CrAg screened, 56/255 (22.0\%, 95\% $\mathrm{Cl}, 17.0-27.5 \%)$ had cryptococcal antigenemia, of whom $47 / 56(83.9 \%, 95 \% \mathrm{Cl}, 71.7-92.4 \%)$ were initiated on pre-emptive therapy with fluconazole and $8 / 47(17.0 \%, 95 \% \mathrm{Cl}, 7.6-30.8 \%)$ of these were still receiving antifungal therapy at 6 months follow up. Atleast one CNS symptom was present in 70\% (39/56) of those with antigenemia. In patients who had started ART, almost 40\% initiated ART prior to CrAg screening. Inadequacy of equipment/supplies was reported by $15 / 26(58 \%)$ of personnel as a program barrier, while $13 / 26$ (50\%) reported a need for training about CM and CrAg screening.

\section{Conclusion:}

There was a critical gap in the follow-up of patients after initiation on fluconazole therapy. ART had been initiated in almost $40 \%$ of patients prior to CrAg screening, which predisposes them to unmasking Cryptococcal IRIS. Higher antigenemia patients presenting with CNS symptoms could be related to late presentation. There is need to address these gaps after a more thorough evaluation.

\section{Background}


Cryptococcus neoformans is the most common cause of meningitis among Human Immunodeficiency Virus (HIV) infected adults in sub-Saharan Africa (SSA), and it is associated with approximately $20-25 \%$ of acquired immunodeficiency syndrome (AIDS)-related deaths in this region [1-4]. Despite the accelerated access to antiretroviral therapy (ART) in the last decade, mortality among patients with HIVassociated cryptococcal meningitis (CM) has remained relatively high [5-7], and SSA carries a disproportionate burden of new infections $[4,8,9]$. Among patients who complete standard antifungal therapy for $\mathrm{CM}$, survival at two years from diagnosis is $69 \%$ [10], and this proportion is lower in settings without optimal treatment regimens [11].

Infection with $C$. neoformans can be diagnosed using a cryptococcal antigen (CrAg) test in serum/plasma, before the infection progresses and the patient develops meningitis. The current management strategy for $\mathrm{CM}$ includes regimens that are expensive and not always available, especially in resource limited settings $[10,12,13]$. There is evidence demonstrating the cost effectiveness of $\mathrm{CrAg}$ screening and CM pre-emptive therapy in routine HIV care [12, 14-16]. The prevalence of asymptomatic cryptococcal antigenemia in patients with HIV in Uganda with CD $4 \leq 100$ cells/ $\mu$ is estimated between $5-10 \%[17]$.

Asymptomatic patients with a positive CrAg test in blood (antigenemia) will typically develop meningitis in approximately three weeks [18]. This provides a window of opportunity in which treatment with fluconazole as pre-emptive therapy can prevent progression to CM [19].

In order to increase the capacity to detect $\mathrm{CM}$ before it progresses to meningitis in HIV positive patients, a CrAg screening program was initiated in 206 high-volume ( $\geq 1000$ patients) government and private health facilities providing ART in Uganda through the Ugandan Ministry of Health.

The CrAg screening program was initiated after training of key members of the treatment teams for $\mathrm{CDC} / \mathrm{PEPFAR}$ implementing partners. The key members were then tasked to cascade the trainings to facility level. CDC provided the cryptococcal antigen screening kits for use during the roll-out in the 206 chosen health facilities. Since the initiation of the program in April 2016, there has not been a formal evaluation of the operations and outputs of this program. We therefore sought to understand the current operation of the program through; 1) quantification of metrics along the CrAg screening cascade and 2) identification of operational challenges cited by the implementers at selected health facilities.

\section{Methods}

\section{Study design}

We conducted a cross sectional study with a retrospective review of patient records in an electronic medical record (EMR) systems (Open MRS) [20] or in the hard copy CD4 registers. We considered patients that had had a CD4 cell count of $\leq 100$ cells/ $\mu \mathrm{L}$ done from April 2016 to March 2017.

\section{Data collection}


We abstracted data from the OpenMRS $\circledast$ medical records system or the CD4 and CrAg registers. These registers are standard Uganda Ministry of Health $(\mathrm{MoH})$ tools that are used for documentation and generation of routine performance reports on selected CD4, viral load, and CrAg screening indicators from point of diagnosis to point of treatment or pre-emptive fluconazole therapy (CrAg screening cascade). We operationally defined a successful cryptococcal care cascade when: at least $90 \%$ of patients with a CD4 $\leq 100$ get a CrAg test, $90 \%$ of CrAg positive patients start fluconazole, and $90 \%$ of these complete 6 months of fluconazole. We obtained clinic file numbers for every patient with a documented CD4 count $\leq$ 100 cells $/ \mu \mathrm{L}$, and we used the corresponding CrAg register and patient chart for each patient to determine the number that progressed through each level of the cryptococcal care cascade. In addition to the patients' charts and registers reviews, we conducted two interviews in each of the sampled health facilities, one with the laboratory staff and the other with the ART clinic in-charge, to identify barriers and enablers of a successful CrAg screening program at their health facility.

Study sites and setting.

Our evaluation included 14 health facilities located in two urban districts in Central Uganda (Kampala, the Capital of Uganda and Wakiso) and three rural districts in South Western Uganda (Masaka, Rakai, and Ssembabule). The 14 health facilities were at different tiers of the health care system as follows: (1) level III (providing outpatient services, maternity, general ward and laboratory to a population of about 20,000 people); (2) level IV (providing all services at level III and including a theatre and blood transfusion to about 100,000 people); (3) general hospitals (provide all services at level IV and includes $\mathrm{x}$-ray to a population of 100,000-1,000,000 people); and (4) regional referral hospitals (provide all services of general hospitals and includes specialist services to a population of about 1,000,000-2,000,000 people).

\section{Sample size calculation}

Using unpublished sample data from 15 HIV programs implementing partners, we estimated the proportion of patients with CD4 count less than 100 cells $/ \mu \mathrm{L}$ and screened for CrAg to be $19 \%$. Using a $95 \%$ confidence level and an expected error margin of $5 \%$, we expected to review 236 patient charts from each of the two regions, giving an overall sample size of 472 patient charts. We conducted 28 individual interviews, two from each of the participating 14 selected sites, targeting laboratory personnel and the incharge of the ART clinic. With a total of 28 interviews, the number was sufficient to reach saturation of the major themes related to the barriers and facilitators for CrAg screening.

\section{Phase 1: Identification and Initial contact with facilities}

Using the initial CrAg kit distribution list from the infectious diseases institute (IDI) directory, we obtained health facilities' contact information and reached the selected health facilities via telephone ahead of the planned visit/data collection date. During the call, our study personnel explained the study and procedures (abstraction of data from the EMR, registers and charts) and asked about the availability of the laboratory personnel and ART in-charges, and the best days/times to schedule a study visit.

\section{Phase 2: Facility Visits}


Trained study personnel contacted the health facility approximately two days before the planned visit to remind them of the upcoming visit and what to expect during the visit. This was another opportunity for the facility to ask questions about the study. After agreement on the day and time, two study team members then went to the health facilities, did formal introductions and identified the contact person managing the EMR or CD4 registers. Study team members together with the EMR/ CD4 register focal person generated a list of patient IDs with baseline CD $4 \leq 100$ and tracked these in the $\mathrm{CrAg} /$ laboratory register to ascertain whether or not they underwent CrAg screening. When information was not available

or missing from the $\mathrm{CrAg} /$ laboratory register, patient charts were retrieved by peer patients/ expert clients (these are HIV positive patients who have freely disclosed their HIV status and perform low level tasks at HIV clinics including treatment education, file retrieval and taking patients' vitals), and the study team abstracted data related to the CrAg screening program. Figure 1 illustrates the overall CrAg screening cascade. Later in the day or on the second day, the study team located the laboratory personnel and ART in-charge and administered the qualitative interviews after obtaining their consent. All the data from the registers and interviews were directly entered into a REDCap ${ }^{\circledR}[21]$ database administered on a tablet.

\section{Data management and analysis}

We developed data abstraction tools that included variables reflecting the different steps along the $\mathrm{CrAg}$ screening cascade. The study tools were pre-tested at the IDI HIV clinic within Mulago hospital. We then designed a database using REDCap electronic data capture hosted at the University of Minnesota [21, 22]. We included data validation rules within the data capture forms, and data were collected in both online and offline modes. One investigator managed the REDCap database and would inform the data collection team of any errors for immediate correction on a daily basis. A cleaned data set was exported to Stata version 14 (College Station, Texas) [23] for analysis. We summarized baseline CD4 using medians and interquartile ranges (IQR) and categorical variables were summarized using percentages. To test for the equality of proportions and medians between regions, we ran proportion tests for categorical variables, and Mann Whitney tests for median. We presented the overall proportion of patients that completed each step of the cascade using a table and bar graph.

\section{Results}

\section{Chart audit/review findings}

Our analysis included 359 (76.1\%) out of the expected 472 patient charts. As presented in Table 1, all but one health facility were government health facilities, and the majority $(135 / 359,37.6 \%)$ were health centres at level III. 
Table 1

Background characteristics

\begin{tabular}{|c|c|c|c|c|c|c|c|}
\hline \multirow{3}{*}{ Characteristic (s) } & \multirow{3}{*}{ Categories } & \multicolumn{6}{|c|}{ Location of site } \\
\hline & & \multicolumn{2}{|l|}{ Rural } & \multicolumn{2}{|l|}{ Urban } & \multicolumn{2}{|l|}{ All } \\
\hline & & $\mathbf{N}$ & $\%$ & $\mathbf{N}$ & $\%$ & $\mathbf{N}$ & $\%$ \\
\hline \multirow{2}{*}{$\begin{array}{l}\text { Ownership of Health } \\
\text { Facility }\end{array}$} & Government & 149 & 99.3 & 209 & 100.0 & 358 & 99.7 \\
\hline & Private & 1 & 0.7 & & & 1 & 0.3 \\
\hline \multirow[t]{4}{*}{ Health Facility Level } & $\mathrm{HC}$ III & 14 & 9.3 & 121 & 57.9 & 135 & 37.6 \\
\hline & HC IV & 25 & 16.7 & 18 & 8.6 & 43 & 12.0 \\
\hline & $\begin{array}{l}\text { General } \\
\text { Hospital }\end{array}$ & 29 & 19.3 & 40 & 19.1 & 69 & 19.2 \\
\hline & $\begin{array}{l}\text { Referral } \\
\text { Hospital }\end{array}$ & 82 & 54.7 & 30 & 14.4 & 112 & 31.2 \\
\hline \multirow[t]{3}{*}{ Baseline CD 4 cell count } & Median (IQR) & $\begin{array}{l}49(25- \\
71)\end{array}$ & & $\begin{array}{l}44(19- \\
70)\end{array}$ & & $45(21$ & $-71)$ \\
\hline & $<50$ & 77 & 51.3 & 116 & 55.5 & 193 & 53.8 \\
\hline & $50-100$ & 73 & 48.7 & 93 & 44.5 & 166 & 46.2 \\
\hline \multirow{5}{*}{$\begin{array}{l}\text { Baseline WHO clinical } \\
\text { stage }\end{array}$} & 1 & 20 & 13.3 & 45 & 21.5 & 65 & 18.1 \\
\hline & 2 & 52 & 34.7 & 63 & 30.1 & 115 & 32.0 \\
\hline & 3 & 42 & 28.0 & 47 & 22.5 & 89 & 24.8 \\
\hline & 4 & 35 & 23.3 & 54 & 25.8 & 89 & 24.8 \\
\hline & Missing & 1 & 0.7 & & & 1 & 0.3 \\
\hline
\end{tabular}

Of the 359 patients, overall median (IQR) CD 4 cell count was 45 cells/ $\mu \mathrm{L}(21-71), 193$ (53.8\%) had a baseline CD 4 cell count of $<50$ cells/ $\mu \mathrm{L}$ and $178 / 359$ (49.5\%) were classified with WHO clinical stage 3 or 4 HIV disease. As illustrated in Table 2, 255/359 (71.0\% (95\% Cl, 66.0-75.7) of the patients were CrAg screened and the proportion was higher among urban facilities compared to rural facilities $(81.3 \% \mathrm{vs}$ $56.7 \% \mathrm{P}<0.001)$. Ninety four percent $(210 / 255)$ of the CrAg tests were done within seven days of receiving a CD4 count result. Twenty two percent $(56 / 255,95 \% \mathrm{Cl}, 17.0-27.5 \%)$ of patients screened were CrAg positive (had cryptococcal antigenemia). Of the CrAg positive patients, 50/56 $(89.3 \%, 95 \% \mathrm{Cl}, 78.1-$ 96.0) presented with at least one CNS sign or symptom and $39 / 56(69.6 \%, 95 \% \mathrm{Cl}, 55.9-81.2)$ had a lumbar puncture performed. While $39 / 48(81.3 \%(95 \% \mathrm{Cl}, 67.4-91.1)$ of patients with CNS symptoms in urban health facilities had diagnostic lumbar punctures done, none was done in any of the rural health facilities. In patients with confirmed CrAg antigenemia, $47 / 56(83.9 \%, 95 \% \mathrm{Cl}, 71.7-92.4)$ were initiated on fluconazole pre-emptive therapy. At 6 months follow up, 8/47 (17.0\%, 95\% Cl, 7.6-30.8\%) were still 
receiving fluconazole pre-emptive therapy. Among patients who had started ART, nearly 40\% (129/332, $38.9 \%)$ started ART prior to having a CrAg test. 
Table 2

The CrAg Screening Cascade in the Ugandan patients

\begin{tabular}{|c|c|c|c|c|}
\hline \multirow[t]{4}{*}{ Characteristic along the Cascade } & \multicolumn{3}{|l|}{ Site } & \multirow{4}{*}{$\begin{array}{l}\mathrm{P} \text { - } \\
\text { value }\end{array}$} \\
\hline & Urban & Rural & All & \\
\hline & \multirow[t]{2}{*}{$\begin{array}{l}\text { Number: } \\
\text { Proportion \% } \\
(95 \% \mathrm{Cl})\end{array}$} & \multirow[t]{2}{*}{$\begin{array}{l}\text { Number: } \\
\text { Proportion \% } \\
\text { ( } 95 \% \mathrm{Cl})\end{array}$} & $\begin{array}{l}\text { Number: } \\
\text { Proportion } \\
\%\end{array}$ & \\
\hline & & & $(95 \% \mathrm{Cl})$ & \\
\hline Number of patients with $C D 4 \leq 100 \mu / \mathrm{ml}$ & $209(58.2)$ & $150(41.8)$ & $\begin{array}{l}359 \\
(100.0)\end{array}$ & \\
\hline Proportion of patients with CrAg Screen & $\begin{array}{l}\text { 170: } 81.3 \\
(75.4-86.4)\end{array}$ & $\begin{array}{l}\text { 85: } 56.7 \\
(48.3-64.7)\end{array}$ & $\begin{array}{l}\text { 255: } 71.0 \\
(66.0- \\
75.7)\end{array}$ & $<.001$ \\
\hline $\begin{array}{l}\text { Proportion Screened for CrAg within } 7 \text { days } \\
\text { of a CD } 4 \text { test }\end{array}$ & $\begin{array}{l}\text { 138: } 81.2 \\
(74.5-86.8)\end{array}$ & $\begin{array}{l}\text { 72: } 84.7 \\
(75.3-91.6)\end{array}$ & $\begin{array}{l}210: 82.4 \\
(53.4- \\
63.8)\end{array}$ & 0.489 \\
\hline $\begin{array}{l}\text { Proportion of patients with CrAg Screen } \\
\text { contacted with Results }\end{array}$ & $\begin{array}{l}\text { 170: } 100.0 \\
(97.9-100.0)\end{array}$ & $\begin{array}{l}\text { 82: } 96.5 \\
(90.0-99.3)\end{array}$ & $\begin{array}{l}\text { 252: } 98.8 \\
(96.6- \\
99.8)\end{array}$ & 0.014 \\
\hline $\begin{array}{l}\text { Proportion of patients with a CrAg positive } \\
\text { result }\end{array}$ & $\begin{array}{l}48: 28.2 \\
(21.5-35.0)\end{array}$ & $\begin{array}{l}\text { 8: } 9.4(4.2- \\
17.7)\end{array}$ & $\begin{array}{l}56: 22.0 \\
(17.0- \\
27.5)\end{array}$ & 0.001 \\
\hline $\begin{array}{l}\text { Proportion of Patients Screen for signs and } \\
\text { symptoms of CNS infection }\end{array}$ & $\begin{array}{l}43: 89.6 \\
(77.3-96.5)\end{array}$ & $\begin{array}{l}7: 87.5 \\
(47.3-99.7)\end{array}$ & $\begin{array}{l}50: 89.3 \\
(78.1- \\
96.0)\end{array}$ & 0.860 \\
\hline $\begin{array}{l}\text { Proportion of patients in whom a lumbar } \\
\text { puncture was done* }\end{array}$ & $\begin{array}{l}39: 81.3 \\
(67.4-91.1)\end{array}$ & $0: 0(0.0-0.0)$ & $\begin{array}{l}\text { 39: } 69.6 \\
(55.9- \\
81.2)\end{array}$ & \\
\hline $\begin{array}{l}\text { Proportion of patients started on } \\
\text { Prophylaxis }\end{array}$ & $\begin{array}{l}39: 81.3 \\
(67.4-91.1)\end{array}$ & $\begin{array}{l}8: 100.0 \\
(63.1-100.0)\end{array}$ & $\begin{array}{l}47: 83.9 \\
(71.7- \\
92.4)\end{array}$ & 0.181 \\
\hline $\begin{array}{l}\text { Proportion of patients started on } \\
\text { Fluconazole that were still receiving } \\
\text { prophylaxis at } 6 \text { months }\end{array}$ & $\begin{array}{l}\text { 5: } 12.8(4.5- \\
28.8)\end{array}$ & $\begin{array}{l}3: 37.5(8.5- \\
75.5)\end{array}$ & $\begin{array}{l}8: 17.0 \\
(7.6- \\
30.8)\end{array}$ & 0.108 \\
\hline $\begin{array}{l}\text { Proportion of patients who were started on } \\
\text { ART }\end{array}$ & $\begin{array}{l}\text { 183: } 87.6 \\
(82.3-91.7)\end{array}$ & $\begin{array}{l}\text { 149: } 99.3 \\
(96.3-100.0)\end{array}$ & $\begin{array}{l}\text { 332: } 92.5 \\
(89.2- \\
95.0)\end{array}$ & $<$. \\
\hline $\begin{array}{l}\text { Proportion of patients who were started on } \\
\text { ART prior to CrAg screening }\end{array}$ & $\begin{array}{l}\text { 130: } 71.0 \\
(63.9-77.5)\end{array}$ & $\begin{array}{l}\text { 53: } 35.6 \\
(27.9-43.8)\end{array}$ & $\begin{array}{l}\text { 129: } 38.9 \\
(33.6- \\
44.3)\end{array}$ & $\begin{array}{l}< \\
0.001\end{array}$ \\
\hline
\end{tabular}




\begin{tabular}{|c|c|c|}
\hline \multicolumn{3}{|l|}{ Site } \\
\hline Urban & Rural & All \\
\hline \multirow[t]{2}{*}{$\begin{array}{l}\text { Number: } \\
\text { Proportion \% } \\
(95 \% \mathrm{Cl})\end{array}$} & $\begin{array}{l}\text { Number: } \\
\text { Proportion \% } \\
\text { (95\% Cl) }\end{array}$ & $\begin{array}{l}\text { Number: } \\
\text { Proportion } \\
\%\end{array}$ \\
\hline & & $(95 \% \mathrm{Cl})$ \\
\hline $\begin{array}{l}\text { 110: } 52.6 \\
(45.6-59.6)\end{array}$ & $\begin{array}{l}\text { 103: 68.7 } \\
(60.6-76.0)\end{array}$ & $\begin{array}{l}\text { 213: } 59.3 \\
(54.1- \\
64.5)\end{array}$ \\
\hline
\end{tabular}

\section{Barriers for a successful CrAg screening program}

Results of semi-structured interviews of the laboratory personnel and ART clinic in-charges are shown in Table 3 where $58.0 \%$ of the respondents reported lack of sufficient equipment and supplies for the $\mathrm{CrAg}$ screening process while $50 \%$ indicated training gaps in CrAg screening, cryptococcal meningitis management, and lumbar puncture procedures as the main barriers to implementing a successful $\mathrm{CrAg}$ screening program.

Table 3

Areas for improvement as cited by either a laboratory personnel of ART clinic in-charge

\begin{tabular}{|c|c|c|c|}
\hline \multirow[t]{2}{*}{ Barrier(s) cited } & \multicolumn{3}{|l|}{ Respondent } \\
\hline & $\begin{array}{l}\text { Laboratory Personnel } \\
n=13\end{array}$ & $\begin{array}{l}\text { ART clinic In-charge } \\
n=13\end{array}$ & $\begin{array}{l}\text { All respondents } \mathrm{r} \\
=26\end{array}$ \\
\hline $\begin{array}{l}\text { Lack of Equipment and } \\
\text { Supplies }\end{array}$ & $8(62 \%)$ & $7(54 \%)$ & $15(58 \%)$ \\
\hline Inadequate Human resources & $2(15 \%)$ & $2(15 \%)$ & $4(15 \%)$ \\
\hline $\begin{array}{l}\text { Training Gap (Need for a } \\
\text { training) }\end{array}$ & $5(38 \%)$ & $8(62 \%)$ & $13(50 \%)$ \\
\hline $\begin{array}{l}\text { Do not have Guidelines and } \\
\text { Policies }\end{array}$ & $1(8 \%)$ & $1(8 \%)$ & $2(8 \%)$ \\
\hline Logistics & $0(0 \%)$ & $2(15 \%)$ & $2(8 \%)$ \\
\hline
\end{tabular}

\section{Discussion}

In our evaluation study we observed strengths as well as critical gaps along the CrAg screening cascade in patients with lower CD4 cell count. Among eligible patients for CrAg screening, seven out of every ten were subsequently screened, over $80 \%$ of eligible patients was initiated on fluconazole pre-emptive therapy but less than one in five of these were still receiving fluconazole after 6 months, in contrast to the Uganda Ministry of Health guidelines, which recommend six months of fluconazole pre-emptive therapy 
for cryptococcal antigenemia. Lack of supplies and training gaps were identified by health workers as impediments to a successful CrAg screening program.

Knowing the estimates of opportunistic infections among people living with HIV is very crucial in designing prevention strategies and major treatment needs [3], this has been fostered through strategically choosing the order and type of tests to include in the diagnostic algorithms for better care delivery. However, these algorithms need continuous evaluation to identify critical areas for improvement. Cryptococcal antigen screening is a major screening tool among patients with advanced HIV disease aimed at preventing morbidity and mortality due to cryptococcal infection. Integration of routine $\mathrm{CrAg}$ screening and pre-emptive fluconazole therapy in HIV care programs is cost effective with reduction of cryptococcal meningitis and overall reduction in HIV associated mortality.

Our evaluation study found higher CrAg screening in the urban facilities (81.3\%) compared to rural facilities (56.7\%), this may be associated with decreased logistical supplies in the rural areas, In addition, current WHO guideline recommendations of the ART test and treat policy in resource limited settings with decreased access to CD4 machines so as to prevent further delay in ART initiation, which is so profound in the rural areas.

We found a cryptococcal antigenemia prevalence of $22 \%$. This was higher as compared to earlier analyses by Rajasingham et al, which found a global cryptococcal prevalence of $6 \%$ (95\% Cl, 5.8-6.2) [24]. In addition a study by Meya et a/ that assessed the cost effectiveness of serum CrAg screening in HIV patients initiating ART with CD4 $<100$ in resource limited settings in Uganda had a cryptococcal antigenemia prevalence of $8.2 \%$ [25].There has not been a clear reason for such a higher prevalence detected, however this might be associated with the increased roll out of an organised CrAg screening program in the different areas of the country as compared before, with more capture of CrAg screening data, and increased number of ART experienced patients presenting with advanced disease. This could act as an eye opener for epidemiologists and policy makers that the burden of disease might be higher than the current estimates and thus a more thorough evaluation for better channelling of services. A higher percentage of CrAg positive patients had at least one central nervous system (CNS) sign and symptom suggesting a diagnosis of meningitis, which might be explained by the delayed presentation at the facility with advancement of the disease or symptomatic antigenemia and some presenting with subclinical meningitis. Unlike previous studies, a big percentage of patients were ART experienced prior to the CrAg screening with some patients failing on their regimens, recently adherent and others having initiated ART a few weeks prior to screening, exposing this category of patients to a higher risk of developing unmasking cryptococcal meningitis immune reconstitution inflammatory syndrome (CM IRIS). In study by Meya et al, all the 5 cryptococcal antigenemia patients who were initiated on ART but not treated with fluconazole died [25]. Therefore, we propose that these patients have a higher chance of dying despite reaching facilities with better care. Patients screened in the urban centres were more likely to have a diagnostic lumbar puncture as compared to rural facilities. This can be associated to increased availability of specialized and trained health personnel's, logistical supplies and reduced stigma towards lumbar punctures due to improved education status in urban facilities. In addition a lot of patients who 
require services like this are referred from village facilities to urban facilities, as described in the 3 delay model of maternal health seeking [26], some patients end up not making it to the facilities and first seek alternative care like herbal medicine or traditional healers. Some who do so may delay, thus presenting later on with very advanced disease.

Despite the fact that a big percentage of patients were initiated on pre-emptive prophylaxis with fluconazole after having a positive CrAg, six month follow up was significantly low with only $17.0 \%$ still in care and on fluconazole. As demonstrated in number of studies, clinical cryptococcal meningitis develops in a certain number of patients even with pre-emptive fluconazole therapy. Rachel M Wake et al also showed that patients with cryptococcal antigenemia had 3.3 times increased risk of dying as compared to CrAg negative, and this remained significant even when adjusted for baseline CD4 $(<50$ cells/ $\mu \mathrm{L}$ ) [27]. Further, these are patients with severe immunosuppression making them prone to other opportunistic infections before their CD4 counts improve. Thus follow up of these patients after initiating fluconazole pre-emptive therapy is critical and ignoring this gap might undermine all the efforts established to reduce cryptococcal meningitis in Uganda and similar settings in Sub-Saharan Africa.

\section{Study limitations}

As any other retrospect study, we discovered a number of missing files and data despite the fact that patients had met the inclusion criteria, other files had poor documentation that made chart review difficult and others withdrawn from the analysis. Our study was also limited in a way that it could not quantify all the patients that had died during the 6 months follow up outcome as some passed away in the community with no data captured in the patient chart at the facility.

\section{Conclusions}

There is a critical gap in follow up of patients after they initiate pre-emptive fluconazole therapy. A high proportion of patients were ART experienced and presented with advanced HIV disease thus exposing them to an increased risk of unmasking cryptococcal meningitis. There is great need for logistical support, test kits and refresher training of health worker personnel on CrAg screening, cryptococcal meningitis management, and lumbar puncture procedures especially in rural facilities. A more thorough evaluation to identify gaps and successes of the CrAg screening program is / warranted.

\section{Declarations}

\section{Ethics approval and consent to participate}

The study protocol was reviewed by the infectious diseases institute scientific review committee (IDI SRC), and approved by Makerere University School of Public Health Higher Degrees Research and Ethics Committee (MUSPH-HDREC) registration number 508 and final approval sought from Uganda national council for science and technology (UNCST, Registration number SS 4438).In additional administrative clearance was sought through Ministry of health and Health facility incharges to access patients' records 
from selected facilities. All methods and procedures were done following the ethical conduct of human research and in accordance to Declaration of Helsinki. Participants were consented individually, and an informed consent signed willingly after understanding the risks and benefits of participating in the study.

\section{Consent for publication}

Not applicable

\section{Availability of data and material}

All data generated or analysed during this study are included in this published article and its supplementary information files.

\section{Funding}

This study was funded and supported by the Uganda Research Training Collaboration, a program run through the Center for Global Health and Social Responsibility (CGHSR) of the University of Minnesota.

\section{Competing interest}

All authors declare that no financial or non- financial competing interests exists.

\section{Authors' contributions}

EK, JK, BCG, DBM, ASS, participated in the design of the study. In addition, EK and JK supervised data collection and DBA participated in data collection. JK and BCG analysed the data. EK, JK, BCG and DBA wrote the first draft. MKR, JFK, RK, DBM, ASS reviewed the manuscript. All Authors have read and approved the manuscript.

\section{Acknowledgements}

We thank Molly MacCoy, Joshua Rhein and Martha Kandole for their managerial and planning efforts in the initial stages of study and during data collection.

\section{References}

1. Jarvis JN, Meintjes G, Williams A, Brown Y, Crede T, Harrison TS. Adult meningitis in a setting of high HIV and TB prevalence: findings from 4961 suspected cases. BMC Infect Dis. BioMed Central; 2010;10:67-67.

2. Cohen DB, Zijlstra EE, Mukaka M, Reiss M, Kamphambale S, Scholing M, et al. Diagnosis of cryptococcal and tuberculous meningitis in a resource-limited African setting. Trop Med Int Health TM IH. 2010/06/21 ed. England; 2010;15:910-7. 
3. Durski KN, Kuntz KM, Yasukawa K, Virnig BA, Meya DB, Boulware DR. Cost-effective diagnostic checklists for meningitis in resource-limited settings. J Acquir Immune Defic Syndr 1999. 2013;63:e101-8.

4. Rajasingham R, Smith RM, Park BJ, Jarvis JN, Govender NP, Chiller TM, et al. Global burden of disease of HIV-associated cryptococcal meningitis: an updated analysis. Lancet Infect Dis. 2017/05/05 ed. 2017;17:873-81.

5. Srichatrapimuk S, Sungkanuparph S. Integrated therapy for HIV and cryptococcosis. AIDS Res Ther. 2016;13:42.

6. Crabtree Ramírez B, Caro Vega Y, Shepherd BE, Le C, Turner M, Frola C, et al. Outcomes of HIVpositive patients with cryptococcal meningitis in the Americas. Int $J$ Infect Dis. 2017;63:57-63.

7. Azambuja AZ de, Wissmann Neto G, Watte G, Antoniolli L, Goldani LZ. Cryptococcal Meningitis: A Retrospective Cohort of a Brazilian Reference Hospital in the Post-HAART Era of Universal Access. Hoepelman A, editor. Can J Infect Dis Med Microbiol. Hindawi; 2018;2018:6512468.

8. Nyazika TK, Tatuene JK, Kenfak-Foguena A, Verweij PE, Meis JF, Robertson VJ, et al. Epidemiology and aetiologies of cryptococcal meningitis in Africa, 1950-2017: protocol for a systematic review. BMJ Open. 2018;8:e020654.

9. Park BJ, Wannemuehler KA, Marston BJ, Govender N, Pappas PG, Chiller TM. Estimation of the current global burden of cryptococcal meningitis among persons living with HIV/AIDS. AIDS Lond Engl. England; 2009;23:525-30.

10. Kitonsa J, Mayanja Y, Aling E, Kiwanuka J, Namutundu J, Anywaine Z, et al. Factors affecting mortality among HIV positive patients two years after completing recommended therapy for Cryptococcal meningitis in Uganda. PLOS ONE. Public Library of Science; 2019;14:e0210287.

11. Rodríguez J, Villanueva H, Martínez M, Ramírez A, Téllez R, Medina I, et al. Outcomes of HIV positive patients with Cryptococcal meningitis in the absence of optimal treatment: Experience from single institution in Mexico. Int J Infect Dis. Elsevier; 2018;73:242.

12. Meya DB, Manabe YC, Castelnuovo B, Cook BA, Elbireer AM, Kambugu A, et al. Cost-effectiveness of serum cryptococcal antigen screening to prevent deaths among HIV-infected persons with a CD4 + cell count $<$ or $=100$ cells/microL who start HIV therapy in resource-limited settings. Clin Infect Dis Off Publ Infect Dis Soc Am. 2010;51:448-55.

13. Meya D, Rajasingham R, Nalintya E, Tenforde M, Jarvis JN. Preventing Cryptococcosis-Shifting the Paradigm in the Era of Highly Active Antiretroviral Therapy. Curr Trop Med Rep. Springer International Publishing; 2015;2:81-9.

14. Singh N, Barnish MJ, Berman S, Bender B, Wagener MM, Rinaldi MG, et al. Low-dose fluconazole as primary prophylaxis for cryptococcal infection in AIDS patients with CD4 cell counts of $<$ or $=$ 100/mm3: demonstration of efficacy in a positive, multicenter trial. Clin Infect Dis Off Publ Infect Dis Soc Am. United States; 1996;23:1282-6.

15. WHO. Consolidated guidelines on the use of antiretroviral drugs for treating and preventing HIV infection Recommendations for a public health approach - Second edition [Internet]. Second Edition. 
WHO; [cited 2019 Feb 21]. Available from: https://www.who.int/hiv/pub/arv/arv-2016/en/

16. WHO. Guidelines for the diagnosis, prevention and management of cryptococcal disease in HIV infected adults, adolescents and children: Supplement to the 2016 consolidated guidelines on the use of antiretroviral drugs for treating and preventing HIV infection [Internet]. Geneva, Switzerland: World Health Organisation; 2018. Available from: https://apps.who.int/iris/bitstream/handle/10665/260399/9789241550277-eng.pdf

17. Ministry of Health, Uganda. Addendum to the national antiretroviral treatment guidelines [Internet]. Kampala, Uganda: Ministry of Health; 2013 Dec p. 28. Available from: https://aidsfree.usaid.gov/sites/default/files/tx_uganda_add_to_art_2013.pdf

18. French N, Gray K, Watera C, Nakiyingi J, Lugada E, Moore M, et al. Cryptococcal infection in a cohort of HIV-1-infected Ugandan adults. AIDS Lond Engl. England; 2002;16:1031-8.

19. Saag MS, Graybill RJ, Larsen RA, Pappas PG, Perfect JR, Powderly WG, et al. Practice guidelines for the management of cryptococcal disease. Infectious Diseases Society of America. Clin Infect Dis Off Publ Infect Dis Soc Am. 2000/04/20 ed. United States; 2000;30:710-8.

20. OpenMRS [Internet]. 10425 Commerce Dr Ste. 110 Carmel, IN 46032 - 7643, USA: OpenMRS, Inc; Available from: https://openmrs.org/

21. Harris PA, Taylor R, Thielke R, Payne J, Gonzalez N, Conde JG. Research electronic data capture (REDCap)-a metadata-driven methodology and workflow process for providing translational research informatics support. J Biomed Inform. 2008/09/30 ed. 2009;42:377-81.

22. Harris PA, Taylor R, Minor BL, Elliott V, Fernandez M, O’Neal L, et al. The REDCap consortium: Building an international community of software platform partners. J Biomed Inform. 2019;95:103208.

23. Stata Statistical Software [Internet]. College Station, Texas: StataCorp LP; 2015. Available from: http://www.stata.com

24. Rajasingham R, Meya DB, Greene GS, Jordan A, Nakawuka M, Chiller TM, et al. Evaluation of a national cryptococcal antigen screening program for HIV-infected patients in Uganda: A costeffectiveness modeling analysis. PLOS ONE. Public Library of Science; 2019;14:e0210105.

25. Meya DB, Manabe YC, Castelnuovo B, Cook BA, Elbireer AM, Kambugu A, et al. Cost-effectiveness of serum cryptococcal antigen screening to prevent deaths among HIV-infected persons with a CD4 + cell count $<$ or $=100$ cells/microL who start HIV therapy in resource-limited settings. Clin Infect Dis Off Publ Infect Dis Soc Am. 2010;51:448-55.

26. Thaddeus S, Maine D. Too far to walk: Maternal mortality in context. Soc Sci Med. 1994;38:1091110.

27. Wake RM, Govender NP, Omar T, Nel C, Mazanderani AH, Karat AS, et al. Cryptococcal-related Mortality Despite Fluconazole Preemptive Treatment in a Cryptococcal Antigen Screen-and-Treat Program. Clin Infect Dis Off Publ Infect Dis Soc Am. 2020;70:1683-90.

\section{Figures}




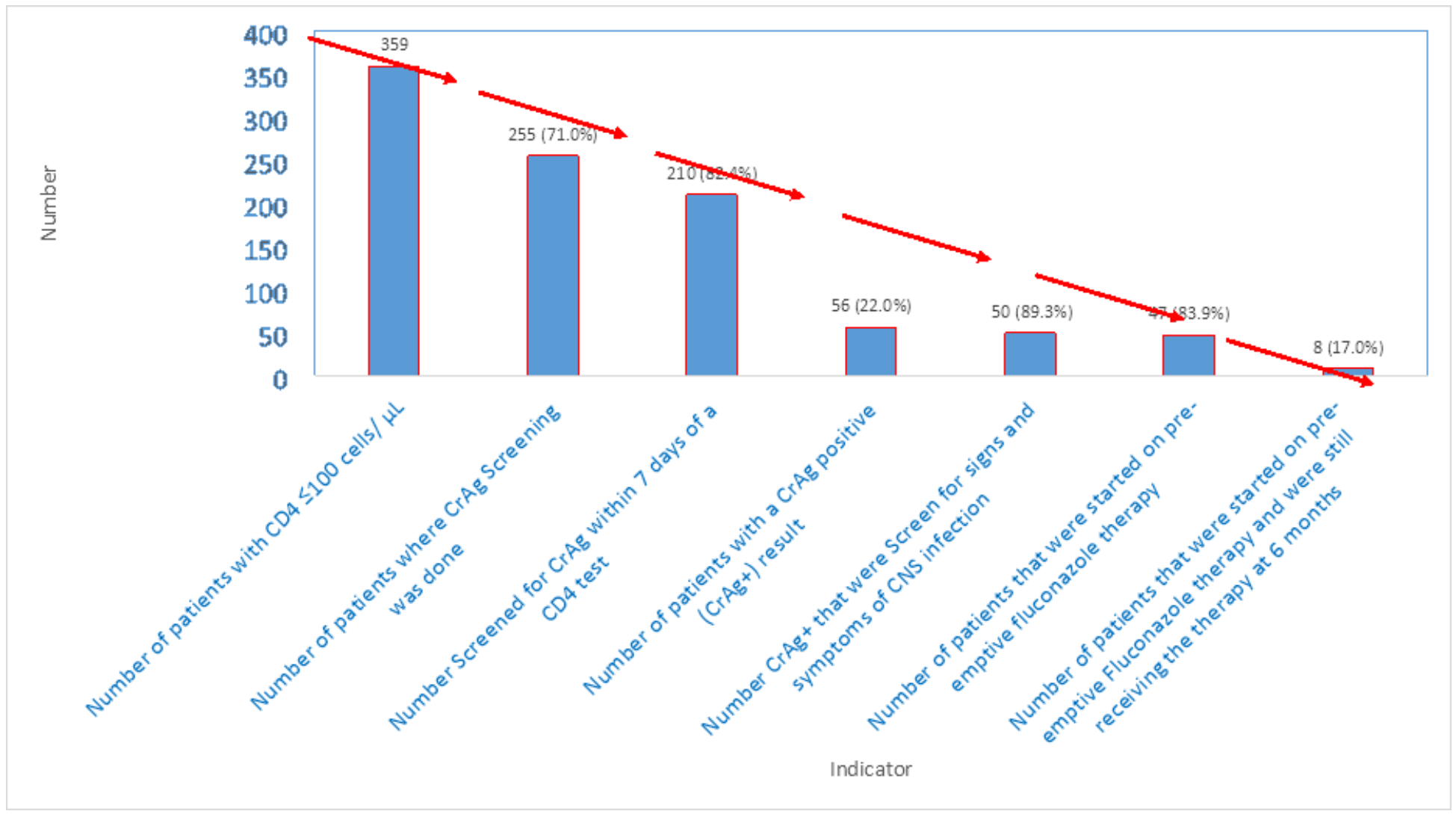

Figure 1

Indicators along the CrAg Screening Cascade 